\title{
Validity of the FACIT-Sp to Assess Spiritual Well-Being in Elderly Patients
}

\author{
Stéfanie Monod ${ }^{*}$, Estelle Lécureux ${ }^{1}$, Etienne Rochat 1,2 , Brenda Spencer ${ }^{3}$, \\ Laurence Seematter-Bagnoud1,3, Anne-Sylvie Martin-Durussel1,2, Christophe Büla1 \\ ${ }^{1}$ Service of Geriatric Medicine \& Geriatric Rehabilitation, University of Lausanne Medical Center (CHUV), \\ Lausanne, Switzerland \\ ${ }^{2}$ Chaplaincy Service, University of Lausanne Medical Center (CHUV), Lausanne, Switzerland \\ ${ }^{3}$ Institute of Social and Preventive Medicine, University of Lausanne Medical Center (CHUV), Lausanne, \\ Switzerland \\ Email: ${ }^{*}$ Stefanie.monod-zorzi@chuv.ch
}

Received 6 April 2015; accepted 10 August 2015; published 13 August 2015

Copyright @ 2015 by authors and Scientific Research Publishing Inc.

This work is licensed under the Creative Commons Attribution International License (CC BY). http://creativecommons.org/licenses/by/4.0/

(c) (i) Open Access

\section{Abstract}

Among instruments measuring spiritual well-being, the Functional Assessment of Chronic Illness Therapy-Spiritual well-being (FACIT-Sp-12) is the most widely used instrument in research. It has been validated in patients suffering from cancer or HIV/AIDS, but has rarely been used in elderly patients. The objectives of this study were to determine the psychometric properties and suitability of the FACIT-Spto assess spiritual well-being in hospitalized elderly patients. This cross-sectional study uses a mixed method approach. Subjects were patients $(\mathrm{N}=208)$, aged 65 years and older, consecutively admitted in post-acute rehabilitation. Psychometric properties of the FACITSp were investigated. The internal structure of the FACIT-Sp (factor structure and internal consistency) was assessed. Convergent validity of the FACIT-Sp was assessed using the Spiritual Distress Assessment Tool (SDAT), the question "Are you at peace?" and the Geriatric Depression Scale (GDS). Predictive validity was assessed using length of stay (LOS) and discharge destination. Understanding and interpretation of FACIT-Sp items were consecutively assessed in a sub-sample of 135 patients. Results show that FACIT-Sp scores ranged from 7 to 46 (mean $29.6 \pm 7.8$ ); $23.1 \%$ of the patients had high spiritual well-being. Cronbach's $\alpha$ was good $(0.85)$. Item-to-total correlations were all significant ( 0.34 to 0.73$)$. Principal component analyses performed with 2 or 3 factors were only moderately consistent with previous work. FACIT-Sp correlated with SDAT, "Are you at peace?" and GDS (Rho $=-0.45, P<0.001 ; 0.51, P<0.001$ and $-0.38, P<0.001$ ). No association was found with LOS or discharge destination. Spontaneous comments about one or more FACIT-Sp items were made by $97 / 135$ (71.9\%). Specifically, items that address purpose and meaning in life were frequently found difficult to answer. Analyses suggest that the FACIT-Sp may underestimate spiritual well-being in older patients. In conclusion, despite having acceptable psychometric properties,

\footnotetext{
${ }^{*}$ Corresponding author.
}

How to cite this paper: Monod, S., Lécureux, E., Rochat, E., Spencer, B., Seematter-Bagnoud, L., Martin-Durussel, A.-S., \& Büla, C. (2015). Validity of the FACIT-Sp to Assess Spiritual Well-Being in Elderly Patients. Psychology, 6, 1311-1322. 
the FACIT-Sp presents limitations for measurement of spiritual well-being in hospitalized elderly patients.

\section{Keywords}

\section{Spirituality, Spiritual Well-Being, Psychometrics, Elderly, Quality of Life}

\section{Introduction}

Spirituality has received increasing attention in the medical literature these last decades, not only in end-of-life care, but also in the broader context of chronic care (Puchalski, 2001; Puchalski, 2009). While there is no consensus on one definition of spirituality within health care, spirituality is usually clearly differentiated from religion (Miller \& Thorensen, 2003; Delgado-Guay et al., 2011; Sessanna et al., 2011). Definitions often includes a sense of transcendence and other dimensions such as purpose and meaning in life, reliance on inner resources, and a sense of within-person integration or connectedness (Chandler et al., 1992; Fry, 2000; Howden, 1992; Moberg, 2005).

Many studies have documented significant associations between spirituality and mental, physical and functional health in chronically ill adults (Koenig, 2012; Hill \& Pargament, 2003). Spirituality is usually considered as a positive resource that may modulate coping with health problems (Kirby et al., 2004; Krause, 2003; Thune-Boyle et al., 2006; Davison \& Jhangri, 2013; Delgado, 2007). However, some findings also suggest that spirituality might also negatively influence health outcomes. "Religious struggle" (e.g.: feeling punished or abandoned by God) has been associated with increased mortality in elderly patients (Pargament et al., 2001; Pargament et al., 2004). Similarly, "spiritual distress", that may be defined as the presence of unmet spiritual needs (Monod et al., 2012; Carpenito, 2004) or "low spiritual well-being” have been associated with depression, desire for hastened death in end-of-life patients and potential harmful effects on patients' prognosis and quality of life (Astrow et al., 2007; Grant et al., 2004; McClain et al., 2003; Rodin et al., 2009). Based on these observations, the need to carefully assess the spirituality dimension among patients is increasingly acknowledged.

Most instruments developed to measure spirituality in clinical research measure behaviors, attitudes, or beliefs towards religion or spirituality. Some may also capture the patient's current spiritual state (Monod et al., 2011), such as instruments measuring spiritual well-being (Canada et al., 2008). Among those instruments measuring spiritual well-being, the Functional Assessment of Chronic Illness Therapy-Spiritual well-being (FACIT-Sp-12) (Brady et al., 1999; Peterman et al., 2002) (12-item scale) is the most widely used instrument in research. It belongs to the larger FACIT measurement system developed to evaluate health-related quality of life. FACIT-Sp originally includes two subscales, measuring "Meaning/Peace" and "Faith". As stated by Peterman in the original validation study of the FACIT-Sp (Peterman et al., 2002), the "Meaning/Peace" subscale measures "a sense of meaning, peace, and purpose in life", whereas the "Faith" subscale measures "several aspects of the relation between illness and one's faith and spiritual beliefs". The FACIT-Sp has previously been validated in patients suffering from cancer or HIV/AIDS and has been shown to have good internal consistency (Cronbach $\alpha 0.87$ ) and concurrent validity with measures of quality of life (Peterman et al., 2002). A three-factor solution of the FACIT-Sp ("Meaning", "Peace" and "Faith" factors) has also been proposed by Canada et al. (Canada et al., 2008) with the hypothesis that the "Meaning" factor would capturea cognitive dimensionof spirituality, whereas a more affective component of spirituality would be included in the "Peace" factor. This three-factor model has further been confirmed by Murphy et al. (Murphy et al., 2010; Whitford \& Olver, 2012).

FACIT-Sp has essentially been used in cancer and HIV/AIDS populations. It has rarely been used in elderly patients. To our knowledge, aside from a study on elderly patients suffering from heart failure $(\mathrm{N}=60$; median age 75 years) (Bekelman et al., 2010), very little is known about its performance in an elderly population. If the FACIT-Sp is to be used in this population, its validity and reliability for the assessment of spiritual well-being must be assessed. Finding the best care options for elderly patients is often complex because these patients frequently present an entanglement of medical, functional, psychological and social problems. Defining the best option of care implies taking into account the patients' preferences, values and what could make sense for them (Mattingly, 1994). Thus, integrating the spiritual dimension into the care of elderly patients is a way to improve 
care for these patients (Sulmasy, 2002; Sulmasy, 2006). Further research is therefore needed to improve our knowledge about the relationship between spirituality and health-related quality of life in the elderly population (Mak, 2011).

The aim of this study was to investigate the validity and suitability of the FACIT-Sp for assessing spiritual well-being in a cohort of older patients admitted to rehabilitation. Specifically, the first objective was to investigate the psychometric properties of the FACIT-Sp in this population. The internal structure of the FACIT-Sp (factor structure and internal consistency), as well as its convergent and predictive validity, were also assessed. The second objective was to investigate the understanding and interpretation of FACIT-Sp items by these elderly patients.

\section{Methods}

\subsection{Participants}

Participants were patients included in a study aiming at measuring spiritual distress in elderly patients hospitalised in rehabilitation (Monod et al., 2012). In this study, the FACIT-Sp and the question “Are you at peace?” were both used to assess convergent validity of the Spritual Distress Assessment Tool (SDAT), an instrument aimed at measuring unmet spiritual needs. The current work uses the data collected for this main study.

Participants were patients aged 65 years or older consecutively admitted over a 6-month period to a geriatric post-acute rehabilitation unit, University of Lausanne Medical Center, Switzerland. Eighty percent of the population served by this hospital reports a Judaeo-Christian religious background (42\% Roman Catholics, 33\% Reformed, $2 \%$ Evangelists, $2 \%$ Orthodox, $0.2 \%$ Jewish). Around $60 \%$, respectively $30 \%$ of all patients admitted in this setting are admitted after an acute care stay in a medical or traumatology/orthopaedic ward, respectively.

Patients unable to speak French and those too ill to complete the interview, because of uncontrolled symptoms such as pain or dyspnoea, were excluded. Patients with significant cognitive impairment, defined as a score lower than 20 on the Mini Mental State Exam (MMSE) (Folstein et al., 1975), were considered ineligible as it was considered that they would not be capable of providing accurate responses to the study questions.

Over the 6-month inclusion period, 305 of the 410 (74.4\%) patients admitted to the rehabilitation unit were found eligible. In the case of multiple admissions during the study period, only the first stay was considered. Within three days following admission, patients were asked by a research assistant to participate in the study. Ninety seven of the 305 (31.8\%) eligible patients refused, resulting in a final sample of 208 patients. Analyses comparing characteristics of patients who refused to participate with those who participated showed no significant differences (Table 1).

The study was approved by the institutional ethical committee and written informed consent was obtained from all study participants.

\subsection{Data Collection}

Information on medical, functional, and mental status is routinely collected upon admission to this rehabilitation hospital. These data includedemographics, living arrangements, observed performance in basic activities of daily living (ADL) (Katz, 1983) and self-reported performance in instrumental ADLs. Cognitive and affective status

Table 1. Characteristics of participants in comparison with patients who refused to participate.

\begin{tabular}{|c|c|c|c|}
\hline Characteristics & $\begin{array}{l}\text { Study sample } \\
\quad(\mathrm{N}=208)\end{array}$ & $\begin{array}{l}\text { Patients who refused to } \\
\text { participate }(\mathrm{N}=97)\end{array}$ & $P$-val Wilcoxon or Chi2 \\
\hline Age (mean) year & $81.4 \pm 7.1$ & $80.8 \pm 6.9$ & 0.361 \\
\hline Women (\%) & 69.568 .3 & 66.0 & 0.545 \\
\hline Living alone (\%) & 55.9 & 58.5 & 0.719 \\
\hline Cognitive impairment ${ }^{*}(\%)$ & 15.9 & 16.5 & 0.890 \\
\hline Depressive Symptoms $^{\dagger}(\%)$ & 14.4 & 12.4 & 0.594 \\
\hline Basic ADL at admission ${ }^{\ddagger}$ & $3.4 \pm 1.5$ & $3.1 \pm 1.5$ & 0.195 \\
\hline
\end{tabular}

${ }^{*}$ Cognitive impairment defined as a MMSE score $<24$ (Folstein et al., 1975). ${ }^{\dagger}$ Depressive symptoms defined as GDS score $\geq 6$ (Yesavage et al., 1982). ${ }^{\ddagger}$ Basic ADL from Katz (Katz, 1983). 
were assessed using the MMSE (Folstein et al., 1975) and 15-item Geriatric Depression Scale (GDS) (Yesavage et al., 1982), respectively. Destination at discharge and hospital length of stay were obtained from hospital administrative database.

Interviews were conducted in privacy in patients' rooms by the research assistant, who administered the two following questionnaires (time to complete ranged from 30 to 40 minutes).

- The Functional Assessment of Chronic Illness Therapy-Spiritual Well-being (FACIT-Sp): The FACIT-Sp is a 12-item scale. Answers are scored on a 5-point Likert scale from 0 to 4 . Total scores range from 0 to 48, higher scores indicating higher spiritual well-being. High spiritual well-being was defined as a FACIT-Sp total score $\geq 36$, as proposed by McClain (McClain et al., 2003). This cut-off was justified on the basis of the labels corresponding to the scores: a score of 3 on the Likert scale indicates "quite a bit" whereas scores below this correspond to "somewhat" or lower.

The FACIT-Sp has been translated into French by the FACIT Organization, using a process of translation-back translation (http://www.facit.org). To our knowledge, no validation of the French version of the FACIT-Sp has been yet performed. Authorization to use the FACIT-Sp was obtained from the FACIT Organization.

- The single question "Are you at peace?": Answers to this question have been strongly correlated with emotional and spiritual well-being in patients with advanced serious illness (Steinhauser et al., 2006), as well as with the FACIT-Sp. Participants were asked to answer on a visual analogue scale, ranging from 0 to 10 , higher scores indicating higher peacefulness.

Subsequent to these assessments, patients were interviewed by a chaplain within 3 to 5 days to assess spiritual distress using the Spiritual Distress Assessment Tool (SDAT). The SDAT is a semi-structured interview performed by a trained chaplain, who assesses spiritual needs on four dimensions (Sense, Transcendence, Values and Identity) (Monod et al., 2012). Scores range from 0 to 15, higher scores indicating higher spiritual distress.

\subsection{Qualitative Data Collection}

On noting the recurrence of remarks made to qualify responses to certain FACIT-Sp items at the beginning of the study (from the first 30 patients), a decision was made to systematically investigate the understanding and interpretation of FACIT-Sp items by these elderly patients. This investigation was done in 135 patients consecutively interviewed by the same research assistant. No significant differences were observed in the characteristics of these 135 patients as compared with the rest of the study population.

Spontaneous comments made by respondents about FACIT-Sp items in the course of questionnaire administration were systematically collected by the research assistant and noted on the FACIT-Sp sheets next to the corresponding FACIT-Sp item. Difficulties in item ratings were systematically noted in the words of the patient, and were then investigated through follow-up questions about statement understanding, ambiguity of meaning, or any other difficulties or discomfort in answering. (e.g.: "why do you find this item difficult to rate?"). With the exception of item 11, the research assistant only sought clarification in those patients who expressed difficulties in itemrating. Additionally, as a negative answer to item 11 "My illness has strengthened my faith or spiritual beliefs" could reflect either absence of impact of the illness on faith or a negative impact of the illness on faith (i.e. religious struggle), the research assistant systematically asked patients who rated low on this item ("not at all"; score $=0$ ) what their negative score meant to them.

Comments about each FACIT-Sp item were combined and content analysis performed to determine those raising most difficulties and to identify emerging themes.

\subsection{Statistical Analysis}

Statistical analyses were performed using Stata (Version 11.0; Stata Corp, College Station, TX).

Descriptive statistics were used to describe the characteristics of study participants. Non-parametric tests were used to compare participants with high and low spiritual well-being.

A confirmatory factor analysis with varimax rotation using a two-factor model, as described by Peterman in the original validation study of the FACIT-Sp (Peterman et al., 2002), and a three-factor model, such as the one used in Canada' s study (Canada et al., 2008), were successively used to compare previous results with those in our population. Principal component analysis was also conducted and produced a two-factor and a three-factor model (without constraint to the factors found in Peterman's or in Canada's studies) assessing the structure of 
the instrument in our population.

Internal consistency of the FACIT-Sp was assessed using Spearman's coefficient from inter-item and itemto-total correlation analyses. Internal reliability was assessed using Cronbach's $\alpha$ coefficient on the global score and on each sub-scores ("Meaning/Peace" and "Faith") separately.

Convergent validity was assessed using Spearman's Rho from correlation analyses with SDAT scores, the single question “Are you at peace?” and the GDS, all used as continuous variables. Predictive validity was first assessed using Spearman's Rho correlations between FACIT-Sp scores and rehabilitation length of stay (LOS). LOS was considered as a proxy for rehabilitation success, with the hypothesis that patients with lower spiritual well-being could have slower improvement in ADL. Dichotomization of FACIT-Sp scores was used to test for association between spiritual well-being and destination at discharge (Chi square tests).

Finally, the population who expressed difficulties in answering an item was stratified according to answers to this item. Non parametric tests were then performed to compare FACIT-Sp total scores across each sub-population to investigate the impact of these items' singular interpretation on FACIT-Sp total score.

\section{Results}

\subsection{Population Characteristics}

Characteristics of the study participants and comparisons between those with high and low (FACIT-Sp total score $\geq 36$ and $<36$, respectively) spiritual well-being are summarized in Table 2 .

Overall, 48 (23.1\%) patients had high spiritual well-being. Those with low spiritual well-being did not significantly differ from patients with higher spiritual well-being, except for the presence of depressive symptoms, which were more frequent in patients with low scores on FACIT-Sp.

\subsection{Psychometric Properties of the FACIT-Sp}

\subsubsection{Factor Analysis}

First, a confirmatory factor analysis was performed for Peterman's two-factor solution and for Canada's three-

Table 2. Population characteristics and comparisons between participants with high and low spiritual well-being.

\begin{tabular}{|c|c|c|c|c|}
\hline \multirow[t]{2}{*}{ Characteristics } & \multirow[t]{2}{*}{$\begin{array}{l}\text { Total population } \\
\quad(\mathrm{N}=\mathbf{2 0 8})\end{array}$} & \multicolumn{2}{|c|}{ Spiritual well-being? } & \multirow[t]{2}{*}{$P$-value ${ }^{*}$} \\
\hline & & High $(N=48)$ & Low $(N=160)$ & \\
\hline Mean Age (years) & $81.4 \pm 7.1$ & $81.6 \pm 7.1$ & $81.3 \pm 7.1$ & 0.747 \\
\hline Women (\%) & 68.3 & 72.9 & 66.9 & 0.430 \\
\hline Living alone (\%) & 55.9 & 60.4 & 54.5 & 0.469 \\
\hline Basic $\mathrm{ADL}^{\dagger}$ at admission & $3.4 \pm 1.5$ & $3.7 \pm 1.5$ & $3.3 \pm 1.5$ & 0.121 \\
\hline Instrumental $\mathrm{ADL}^{\ddagger}$ & $5.4 \pm 2.4$ & $5.8 \pm 2.3$ & $5.3 \pm 2.4$ & 0.218 \\
\hline Cognitive impairment ${ }^{\S}(\%)$ & 15.9 & 14.6 & 16.4 & 0.769 \\
\hline Depressive Symptoms' (\%) & 14.4 & 2.1 & 18.1 & 0.006 \\
\hline FACIT-Sp (range) & $\begin{array}{c}29.6 \pm 7.8 \\
(7-46)\end{array}$ & $\begin{array}{c}38.2 \pm 2.2 \\
(36-46)\end{array}$ & $\begin{array}{c}27.0 \pm 7.0 \\
(7-35)\end{array}$ & $<0.001$ \\
\hline FACIT-Sp, Meaning/Peace subscale (range) & $\begin{array}{c}21.5 \pm 5.1 \\
(5-31)\end{array}$ & $\begin{array}{c}26.3 \pm 1.5 \\
(23-31)\end{array}$ & $\begin{array}{l}20.0 \pm 4.9 \\
(5-27)\end{array}$ & $<0.001$ \\
\hline FACIT-Sp, Faith subscale (range) & $\begin{array}{c}8.1 \pm 3.6 \\
(0-15)\end{array}$ & $\begin{array}{c}11.8 \pm 1.6 \\
(9-15)\end{array}$ & $\begin{array}{l}7.0 \pm 3.3 \\
(0-13)\end{array}$ & $<0.001$ \\
\hline “Are you at peace” (range) & $\begin{array}{l}7.1 \pm 2.3 \\
(0-10)\end{array}$ & $\begin{array}{l}8.4 \pm 1.53 \\
(5-10)\end{array}$ & $\begin{array}{c}6.7 \pm 2.3 \\
(0-10)\end{array}$ & $<0.001$ \\
\hline Discharge home (\%) & 83.7 & 87.5 & 82.5 & 0.411 \\
\hline Mean hospital length of stay & $24.8 \pm 16.0$ & $22.3 \pm 13.0$ & $25.5 \pm 16.8$ & 0.197 \\
\hline
\end{tabular}

${ }^{*} P$ values from non-parametric tests. ${ }^{\dagger}$ Basic ADL from Katz. Scores range from 0 to 6 , higher scores indicating higher independance. ${ }^{\ddagger}$ Instrumental ADL from Lawton (1969). Scores range from 0 to 8, higher scores indicating higher independence. ${ }^{\S}$ Cognitive impairment defined as a MMSE score

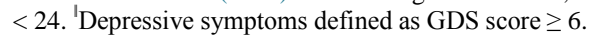


factor solution. Both were significantly found not to fit our population (for both, $P<0.001$ ).

Principal component analysis was then performed with two factors and varimax rotation (Table 3).

This two-factor solution explained $51 \%$ of the variance and was moderately consistent with the proposed "Meaning/Peace" and "Faith” subscales described in Peterman's initial validation study (Peterman et al., 2002). Several differences may be observed between results from these two factor analyses (Figure 1).

First, item 6 ("I am able to reach down deep into myself for comfort") clearly loads on the "Faith" dimension in the current analysis, while it was attributed to the "Meaning/Peace" dimension in Peterman's results. Second, item 3 ("My life has been productive") weighted too low on each factor to be clearly attributed to one particular dimension in the current study, whereas it loaded on "Meaning/Peace" in Peterman's study. Finally, in the current

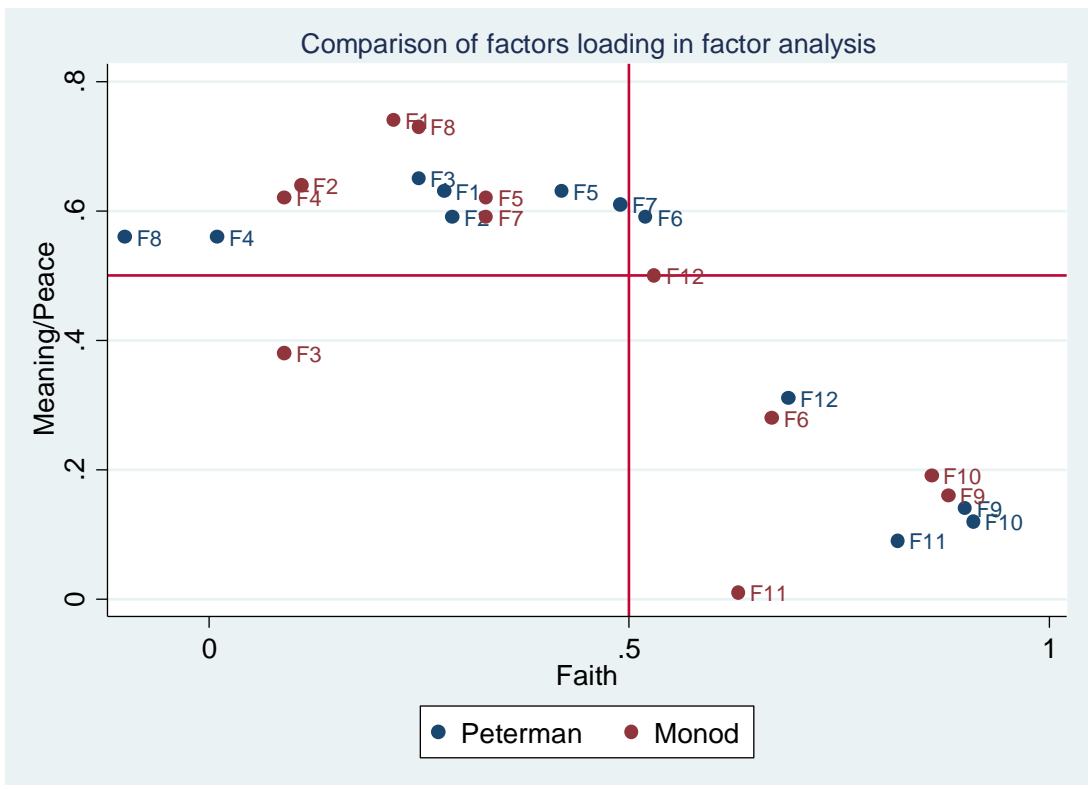

Figure 1. Comparison of factor loadings in factor analysis.

Table 3. Principal component analysis of the FACIT-Sp 12 with two-factor and three-factor solutions.

\begin{tabular}{|c|c|c|c|c|c|c|}
\hline & \multirow[b]{2}{*}{ FACIT-Sp 12 Item } & \multicolumn{2}{|c|}{ Two-factor analysis } & \multicolumn{3}{|c|}{ Three-factor analysis } \\
\hline & & Factor1 & Factor2 & Factor 1 & Factor 2 & Factor 3 \\
\hline 1 & I feel peaceful & 0.74 & 0.22 & 0.32 & 0.74 & 0.18 \\
\hline 2 & I have a reason for living & 0.64 & 0.11 & 0.84 & 0.08 & 0.08 \\
\hline 3 & My life has been productive & 0.38 & 0.09 & -0.08 & 0.62 & 0.07 \\
\hline 4 & I have trouble finding peace of mind & 0.62 & 0.09 & 0.32 & 0.57 & 0.05 \\
\hline 5 & I feel a sense of purpose in my life & 0.62 & 0.33 & 0.80 & 0.11 & 0.29 \\
\hline 6 & I am able to reach down deep into myself for comfort & 0.28 & 0.67 & 0.14 & 0.31 & 0.66 \\
\hline 7 & I feel a sense of harmony within myself & 0.59 & 0.33 & 0.14 & 0.72 & 0.29 \\
\hline 8 & My life lacks meaning and purpose & 0.73 & 0.25 & 0.68 & 0.37 & 0.21 \\
\hline 9 & I find comfort in my faith or spiritual beliefs & 0.16 & 0.88 & 0.15 & 0.14 & 0.88 \\
\hline 10 & I find strength in my faith or spiritual beliefs & 0.19 & 0.86 & 0.20 & 0.14 & 0.85 \\
\hline 11 & My illness has strengthened my faith or spiritual beliefs & 0.01 & 0.63 & 0.10 & -0.04 & 0.63 \\
\hline 12 & $\begin{array}{l}\text { I know that whatever happens with my } \\
\text { illness, things will be okay }\end{array}$ & 0.50 & 0.53 & 0.30 & 0.44 & 0.50 \\
\hline
\end{tabular}

Loadings greater than 0.5 are in bold. 
study, item 12 ("I know that whatever happens with my illness, things will be okay") loaded equally on the two dimensions "Meaning/Peace" and "Faith" and could not be attributed to one single dimension.

A three-factor principal component analysis was then performed (Table 3) and explained $61 \%$ of the variance. It was moderately consistent with Canada's model (Canada et al., 2008). Again, item 3 weighted very low on the "Meaning" factor and was rather attributed to the "Peace" factor. Item 6 could not be attributed to the "Peace" factor and was rather attributed to the "Faith" factor, as in the original two-factor model. On the other hand, in this three-factor model, item 12 is more clearly attributed to the "Faith" dimension.

Overall, neither of the two previously reported models can be considered superior to the other in the studied population.

\subsubsection{Internal Reliability (Table 4)}

Item-to-total correlations were all significant, ranging from 0.34 to 0.73 . Items 3 and 11 had the lowest itemto-total correlation (respectively 0.34 and 0.50 ) across the 12 -item scale.

Internal consistency was good for the total score (Cronbach's $\alpha 0.85$ ) and improved when item 11 was omitted. Cronbach's $\alpha$ for the "Meaning/Peace" and "Faith" subscales were also good ( 0.80 and 0.77 , respectively).

\subsubsection{Validity Assessment}

Assessment of convergent validity showed that the FACIT-Sp total score and the "Meaning/Peace" and "Faith" subscales significantly correlated negatively with spiritual distress scores (Spearman's Rho $=-0.45,-0.50$ and -0.26 , respectively, all $P<0.001)$. FACIT-Sp also correlated significantly with the question "Are you at peace" (Spearman's Rho $=0.51, P<0.001$ ). The "Meaning/Peace" and "Faith" subscales were also positively correlated with the single question (Rho $=0.38$ and 0.51 respectively, all $P<0.001$ ). FACIT-Sp showed a negative correlation with the GDS (Rho $=-0.38, P=0.000$ ). The "Meaning/Peace" and "Faith" subscales also correlated negatively with GDS (Rho $=-0.45, P=0.000$ and Rho $=-0.20, P=0.005$ respectively).

Finally, predictive validity was assessed using correlation between FACIT-Sp scores and hospital length of stay and destination at discharge. No significant correlations were found between hospital length of stay and the FACIT-Sp total score (Rho $=-0.10, P=0.17)$ or the "Meaning/Peace" (Rho $=-0.11, P=0.13$ ) and "Faith" subscales (Rho $=-0.10, P=0.17$ ).

Table 4. Cronbach's $\alpha$ and inter-item correlations.

\begin{tabular}{|c|c|c|c|c|c|}
\hline & Item & $\begin{array}{l}\text { Item to total } \\
\text { correlation }\end{array}$ & $\begin{array}{l}\text { Item to } \\
\text { Rest }^{*}\end{array}$ & $\begin{array}{l}\text { Inter-item } \\
\text { Without }^{\dagger}\end{array}$ & $\begin{array}{c}\text { Cronbach's } \\
\text { Without }^{\ddagger}\end{array}$ \\
\hline 1 & I feel peaceful & 0.66 & 0.59 & 0.37 & 0.84 \\
\hline 2 & I have a reason for living & 0.54 & 0.45 & 0.38 & 0.85 \\
\hline 3 & My life has been productive & 0.34 & 0.26 & 0.41 & 0.85 \\
\hline 4 & I have trouble finding peace of mind & 0.52 & 0.40 & 0.37 & 0.85 \\
\hline 5 & I feel a sense of purpose in my life & 0.68 & 0.59 & 0.34 & 0.83 \\
\hline 6 & $\begin{array}{l}\text { I am able to reach down deep into } \\
\text { myself for comfort }\end{array}$ & 0.66 & 0.57 & 0.35 & 0.84 \\
\hline 7 & I feel a sense of harmony within myself & 0.63 & 0.55 & 0.37 & 0.84 \\
\hline 8 & My life lacks meaning and purpose & 0.69 & 0.61 & 0.35 & 0.83 \\
\hline 9 & I find comfort in my faith or spiritual beliefs & 0.72 & 0.64 & 0.34 & 0.83 \\
\hline 10 & I find strength in my faith or spiritual beliefs & 0.73 & 0.65 & 0.34 & 0.83 \\
\hline 11 & $\begin{array}{l}\text { My illness has strengthened my faith or } \\
\text { spiritual beliefs }\end{array}$ & 0.50 & 0.36 & 0.37 & 0.86 \\
\hline \multirow[t]{2}{*}{12} & $\begin{array}{l}\text { I know that whatever happens with my illness, } \\
\text { things will be okay }\end{array}$ & 0.71 & 0.64 & 0.35 & 0.83 \\
\hline & FACIT-Sp & & & 0.36 & 0.85 \\
\hline
\end{tabular}

* Item to rest: correlation between item and a score composed of all other items. ${ }^{\dagger}$ Inter-item without: average inter-item correlation when the current one is dropped. ${ }^{\ddagger}$ Cronbach’s without: $\alpha$ of the score composed of all items but the current one. 
Patients discharged to home (as compared with discharge to any other destination) had a FACIT-Sp mean score of 29.8 (respectively 28.6), a "Meaning/Peace” subscale mean of 21.5 (respectively 21.2) and a "Faith" subscale mean of 8.2 (respectively 7.3); none of the differences were significant.

\subsection{Understanding and Interpretation of FACIT-Sp Items}

Overall, 97/135 patients (71.9\%) made a total of 192 spontaneous comments on at least one item of the FACITSp (Figure 2).

Comments were most frequently expressed for item 2 "I have a reason for living” (29 patients), item 5 "I feel a sense of purpose in my life” (56 patients), item 8 "My life lacks meaning and purpose” (27 patients), and item 11 "My illness has strengthened my faith or spiritual beliefs" (33 patients). These comments are illustrated below.

Item 2 "I have a reason for living” raised many comments by patients (e.g. "I have no taste for life anymore...”; "I love life!”; "we have no reason for living when we are ill”; “I've been widowed for 9 months...”). Overall, respondents frequently justified a positive answer by mentioning their relationship with their family (11 out of 29 comments; e.g. "I live for my family”; “my husband!”; “my grandchildren!”).

Patients found item 5 "I feel a sense of purpose in my life” and item 8 "My life lacks meaning and purpose” difficult to answer. Remarks were often made to explain why the term "Purpose in life" was felt inappropriate. Some participants were unable to describe what could be their "purpose in life". These items raised issues related to their future life/death/place to live. Some comments were: “I don't want to go into a nursing home..."; "I'm going towards death..."; "I would like God to keep me here as long as possible..."; "Purpose in life is life's accomplishment”; "to stick it out...”; "to stay at home as long as possible...”. Some participants also explained regarding item 8 , that they still had meaning in life but lacked purpose.

Overall, 34 of the 56 participants who made comments on item 5, mentioned their "old age" to justify their lack of purpose in life (e.g. "But, you know... at my age, it's normal to lack purpose in life”). We therefore made the assumption that in patients mentioning their "old age" a low score on item 5 did not necessarily reflect low spiritual well-being. To further investigate this hypothesis in the total sample $(\mathrm{N}=135)$ we dichotomized the item 5 answer as "Low on item 5 " for scores $<3$ and "High on item 5 " for scores $\geq 3$. Among patients with answers “Low on item 5" ( $\mathrm{N}=73 / 135)$, those $(\mathrm{N}=34 / 73)$ mentioning their "old age” to explain their lack of purpose in life had significantly higher FACIT-Sp total scores than those $(\mathrm{N}=39 / 73)$ who did not $(26.4 \pm 7.7$ vs $22.5 \pm 8.1, P=0.02)$.

Finally, the 33 spontaneous comments regarding item 11 "My illness has strengthened my faith or spiritual beliefs", were most frequently made by patients to explain connection with their religious affiliation. As mentioned above, the research assistant also systematically asked patients scoring 0 on this item to explain why they chose this score. Overall, 76 participants scored 0 on item 11. Among these, 36/76 (47\%) patients explained this as no particular influence of illness on their faith, 27/76 (35\%) as a negative influence ("religious struggle”) and the remaining 13/76 patients were not able to explain their answer.

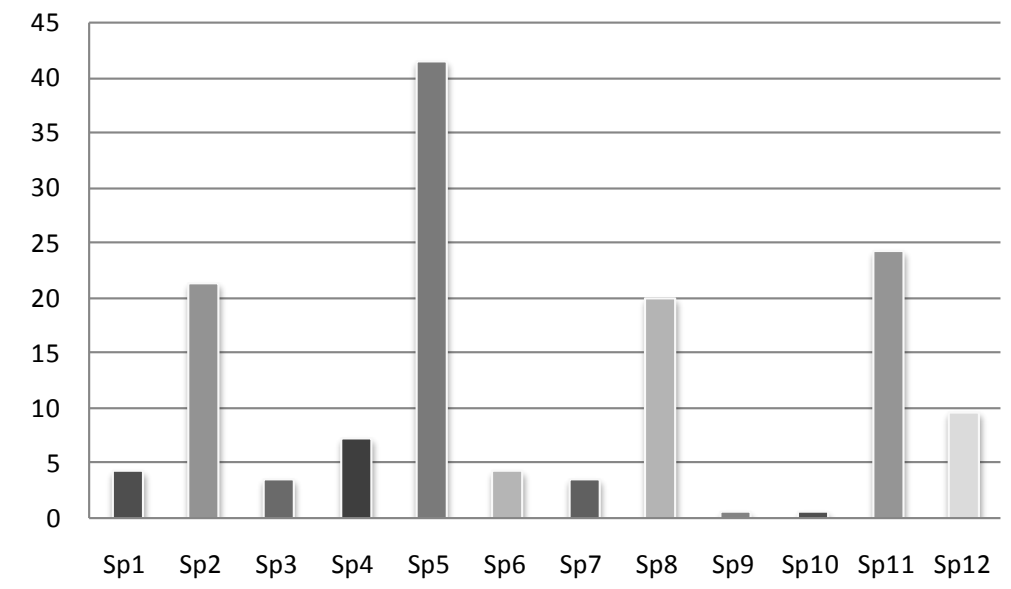

Figure 2. Proportion of patients per item who made comments regarding FACIT-Sp items. 
The hypothesis was tested that total FACIT-Sp scores would differ between patients who expressed religious struggle $(\mathrm{N}=27 / 76)$ and those who did not $(\mathrm{N}=49 / 76)$. Analysis confirmed that patients expressing negative impact of illness on faith or spiritual beliefs had significantly lower FACIT-Sp scores than those who mentioned no impact of illness on their faith $(20.9 \pm 7.9$ vs $30.3 \pm 5.6, P<0.001)$.

\section{Discussion}

This study shows that internal reliability and validity of the FACIT-Sp are acceptable in older patients admitted to rehabilitation. However, some results contrast with those previously reported and suggest that the FACIT-Sp is not fully suited to this specific population. First, the confirmatory factor analyses with two and three factor solutions as obtained by Peterman and Canada respectively did not fit our population. Moreover, principal component analyses performed with two or three factors were only moderately consistent with previously published work. These findings suggest that our results differ somewhat from those of Peterman's and Canada's in a way that cannot simply be attributed to random variation. Overall, these results put into question the content and structure validity of the instrument in this population.

Second, some specificities of older age seem to be inadequately addressed in the FACIT-Sp. In this regard, patients' comments provide insights on older patients' difficulties to answer and rate items that address purpose and meaning in life. In particular, the question about purpose in life (item 5) raised many comments and appeared inappropriate to some of these very elderly patients. Overall, almost half (34/73) of patients who rated having "low" or "no" purpose in life, reported that this was due to their old age without expressing distress in relation to this. Quantitative results also indicated that having no purpose left in life did not necessarily indicate lower spiritual well-being in some older patients, since they had already achieved that which was important for them. Moreover, some patients expressed a lack of purpose but not a lack of meaning in life (item 8), so for these patients the item as presented contained two distinct questions.

Finally, low scores on item 11 could either mean an absence of impact or a negative impact (i.e., religious struggle) of illness on faith. This perceived ambiguity is moreover a priori not specific to an elderly population. Studies have shown that patients suffering from religious struggle have lower spiritual well-being and poorer health outcomes (Pargament et al., 2001; Pargament et al., 2004) than patients who do not express religious struggle. Thus, identical answers to this question can reflect very different states of spiritual well-being.

Interpretation of FACIT-Sp global scores should therefore be made with caution. A unique contribution of this study is to provide evidence that, using this instrument, spiritual well-being might be systematically underestimated in some older patients. These findings would partially explain the relatively low proportion of patients with high spiritual well-being identified in this study when using the cut-off proposed by McClain (23.1\%) (McClain et al., 2003), even if this cut-off is also open to debate.

The Purpose in Life concept seems to be a very interesting way to further explore Spiritual well-being in elderly patients. Patients in this study were very elderly and it not so surprising that such patients could express a lack of purpose in life without expressing distress about it. Nevertheless, some studies found that having a purpose in life was one of the important components of well-being in elderly persons with dementia (Mak, 2011; Boyle et al., 2010). Further research could investigate this question and determine more precisely the relationship between different understandings of Purpose in life and Spiritual well-being (Reker et al., 1987).

An important implication of these observations is that, although the FACIT-Sp is widely used to assess spiritual well-being, its appropriateness in hospitalized elderly patients appears questionable. From a research perspective, other instruments specifically developed to assess spiritual well-being in elderly patients might prove more appropriate. For instance, the Spirituality Index of Well-being (SIWB) (Daaleman et al., 2001; Daaleman \& Frey, 2004; Daaleman et al., 2002) has shown good psychometric properties in a rigorous validation study among community-dwelling geriatric outpatients. This instrument was constructed on the basis of a previously defined conceptual model of spiritual well-being (Daaleman et al., 2001).

This study has some limitations. First, the relatively high refusal rate (31.8\%) might distort interpretation of spiritual well-being prevalence in this population. However, no significant differences were observed between the characteristics of patients who agreed to participate in the study and those who refused. Second, the FACIT-Sp was administered to elderly persons admitted to rehabilitation. Generalization of the conclusions of this study to all elderly people, including those living in the community or in nursing homes, may not be possible. For instance, understanding of Purpose and Meaning in life might significantly differ in these elderly populations. Third, we cannot exclude the possibility that discrepancies found at factor analysis might also partially 
stem from translation and/or insufficient cultural adaptation of the instrument, rather than from differences in the population studied. Although the FACIT-Sp underwent a translation-back-translation process, it has not been validated in a population similar to the one in which it was developed (cancer or HIV patients). Finally, the qualitative analysis was decided upon after having observed a high frequency of comments made by patients regarding certain items. Collection of the comments was therefore not conducted during the earlier interviews. Moreover, spontaneous comments were recorded by the same research assistant, which may have introduced a rater bias (no inter-rater reliability measure). However, content analysis strongly suggests major themes which are consistent with what would have been expected.

This study also has clear strengths. Systematic analysis of comments to assess overall validity and appropriateness of the FACIT-Sp is unique. The relevance and meaning of items for elderly patients has been assessed in detail and these data provided useful information by documenting sources of response error.

\section{Conclusion}

In conclusion, despite having acceptable psychometric properties, the FACIT-Sp may underestimate spiritual well-being in hospitalized elderly patients. Some shortcomings of the instrument observed in this study should encourage researchers to use other instruments designed to assess spiritual well-being in this specific population.

\section{Funding}

This work was supported by the Service of Geriatric Medicine \& Geriatric Rehabilitation, University of Lausanne Medical Center (CHUV), 1011 Lausanne, Switzerland.

\section{Conflict of Interest}

There is no conflict of interest.

\section{Author Contributions}

Stefanie Monod planned the study, supervised the validation of the instrument and wrote the paper. Estelle Lécureux supervised the choice of psychometric analysis and performed all statistical analyses. Brenda Spencer and Laurence Seematter-Bagnoud contributed to the psychometric properties analysis and revised the manuscript. Etienne Rochat and Anne-Sylvie Martin-Durussel collected and analysed patients' comments. Christophe Büla conceptualized the overall methodology and revised the manuscript.

\section{References}

Astrow, A. B., Wexler, A., Texeira, K., He, M. K., \& Sulmasy, D. P. (2007). Is Failure to Meet Spiritual Needs Associated with Cancer Patients' Perceptions of Quality of Care and Their Satisfaction with Care? Journal of Clinical Oncology, 25, 5753-5757. http://dx.doi.org/10.1200/JCO.2007.12.4362

Bekelman, D. B., Parry, C., Curlin, F. A., Yamashita, T. E., Fairclough, D. L., \& Wamboldt, F. S. (2010). A Comparison of Two Spirituality Instruments and Their Relationship with Depression and Quality of Life in Chronic Heart Failure. Journal of Pain and Symptom Management, 39, 515-526. http://dx.doi.org/10.1016/j.jpainsymman.2009.08.005

Boyle, P. A., Buchman, A. S., \& Bennett, D. A. (2010). Purpose in Life Is Associated with a Reduced Risk of Incident Disability among Community-Dwelling Older Persons. American Journal of Geriatric Psychiatry, 18, 1093-1102. http://dx.doi.org/10.1097/JGP.0b013e3181d6c259

Brady, M. J., Peterman, A. H., Fitchett, G., Mo, M., \& Cella, D. (1999). A Case for including Spirituality in Quality of Life Measurement in Oncology. Psycho-Oncology, 8, 417-428.

http://dx.doi.org/10.1002/(SICI)1099-1611(199909/10)8:5<417::AID-PON398>3.0.CO;2-4

Canada, A. L., Murphy, P. E., Fitchett, G., Peterman, A. H., \& Schover, L. R. (2008). A 3-Factor Model for the FACIT-Sp. Psychooncology, 17, 908-916. http://dx.doi.org/10.1002/pon.1307

Carpenito, M. (2004). Nursing Diagnosis: Application to Clinical Practice (10th ed.). Philadelphia: Lippincott Williams \& Wilkins.

Chandler, C. K., Holden, J. M., \& Kolander, C. A. (1992). Counseling for Spiritual Wellness: Theory and Practice. Journal of Counseling \& Development, 71, 168-175. http://dx.doi.org/10.1002/j.1556-6676.1992.tb02193.x

Daaleman, T. P., \& Frey, B. B. (2004). The Spirituality Index of Well-Being: A New Instrument for Health-Related Quali- 
ty-of-Life Research. Annals of Family Medicine, 2, 499-503. http://dx.doi.org/10.1370/afm.89

Daaleman, T. P., Frey, B. B., Wallace, D., \& Studenski, S. A. (2002). The Spirituality Index of Well-Being: Development and Testing of a New Measure. Journal of Family Practice, 51.

Daaleman, T. P., Kuckelman, C. A., \& Frey, B. B. (2001). Spirituality and Well-Being: An Exploratory Study of the Patient Perspective. Social Science \& Medicine, 53, 1503-1511. http://dx.doi.org/10.1016/S0277-9536(00)00439-1

Davison, S. N., \& Janghri, G. S. (2013). The Relationship between Spirituality, Psychosocial Adjustment to Illness, and Health-Related Quality of Life in Patients with Advanced Chronic Kidney Disease. Journal of Pain and Symptom Management, 45, 170-178. http://dx.doi.org/10.1016/j.jpainsymman.2012.02.019

Delgado, C. (2007). Sense of Coherence, Spirituality, Stress and Quality of Life in Chronic Illness. Journal of Nursing Scholarship, 39, 229-234. http://dx.doi.org/10.1111/j.1547-5069.2007.00173.x

Delgado-Guay, M. O., Hui, D., Parsons, H. A., Govan, K., De la Cruz, M., Thorney, S., \& Bruera, E. (2011). Spirituality, Religiosity, and Spiritual Pain in Advanced Cancer Patients. Journal of Pain and Symptom Management, 41, 986-994. http://dx.doi.org/10.1016/j.jpainsymman.2010.09.017

Folstein, M. F., Folstein, S. E., \& McHugh, P. R. (1975). “Mini-Mental State”. A Practical Method for Grading the Cognitive State of Patients for the Clinician. Journal of Psychiatric Research, 12, 189-198. http://dx.doi.org/10.1016/0022-3956(75)90026-6

Fry, P. S. (2000). Religious Involvement, Spirituality and Personal Meaning for Life: Existential Predictors of Psychological Wellbeing in Community-Residing and Institutional Care Elders. Aging \& Mental Health, 4, 375-387. http://dx.doi.org/10.1080/713649965

Grant, E., Murray, S. A., Kendall, M., Boyd, K., Tilley, S., \& Ryan, D. (2004). Spiritual Issues and Needs: Perspectives from Patients with Advanced Cancer and Nonmalignant Disease. A Qualitative Study. Palliative \& Supportive Care, 2, $371-378$. http://dx.doi.org/10.1017/s1478951504040490

Hill, P. C., \& Pargament, K. I. (2003). Advances in the Conceptualization and Measurement of Religion and Spirituality. Implications for Physical and Mental Health Research. American Psychologist, 58, 64-74. http://dx.doi.org/10.1037/0003-066X.58.1.64

Howden, J. W. (1992). Development and Psychometric Characteristics of the Spirituality Assessment Scale. Unpublished Doctoral Dissertation, Houston, TX: Texas Women's University.

Katz, S. (1983). Assessing Self-Maintenance: Activities of Daily Living, Mobility, and Instrumental Activities of Daily Living. Journal of the American Geriatrics Society, 31, 721-727. http://dx.doi.org/10.1111/j.1532-5415.1983.tb03391.x

Kirby, S. E., Coleman, P. G., \& Daley, D. (2004). Spirituality and Well-Being in Frail and Nonfrail Older Adults. The Journals of Gerontology: Series B: Psychological Sciences and Social Sciences, 59, P123-P129. http://dx.doi.org/10.1093/geronb/59.3.p123

Koenig, H. G. (2012). Religion, Spirituality, and Health: The Research and Clinical Implications. ISRN Psychiatry, 2012, Article ID: 278730. http://dx.doi.org/10.5402/2012/278730

Krause, N. (2003). Religious Meaning and Subjective Well-Being in Late Life. The Journals of Gerontology: Series B: Psychological Sciences and Social Sciences, 58, S160-S170. http://dx.doi.org/10.1093/geronb/58.3.s160

Lawton, M. P., \& Brody, E. M. (1969). Assessment of Older People: Self-Maintaining and Instrumental Activities of Daily Living. The Gerontologist, 9, 179-186. http://dx.doi.org/10.1093/geront/9.3_Part_1.179

Mak, W. (2011). Self-Reported Goal Pursuit and Purpose in Life among People with Dementia. The Journals of Gerontology: Series B: Psychological Sciences and Social Sciences, 66, 177-184. http://dx.doi.org/10.1093/geronb/gbq092

Mattingly, C. (1994). The Concept of Therapeutic “Emplotment”. Social Science \& Medicine, 38, 811-822. http://dx.doi.org/10.1016/0277-9536(94)90153-8

McClain, C. S., Rosenfeld, B., \& Breitbart, W. (2003). Effect of Spiritual Well-Being on End-of-Life Despair in Terminally-Ill Cancer Patients. The Lancet, 361, 1603-1607. http://dx.doi.org/10.1016/S0140-6736(03)13310-7

Miller, W. R., \& Thoresen, C. E. (2003). Spirituality, Religion, and Health: An Emerging Research Field. American Psychologist, 58, 24-35. http://dx.doi.org/10.1037/0003-066X.58.1.24

Moberg, D. O. (2005). Research in Spirituality, Religion and Aging. Journal of Gerontological Social Work, 45, 11-40. http://dx.doi.org/10.1300/J083v45n01_02

Monod, S. M., Martin, E., Spencer, B., Rochat, E., \& Bula, C. J. (2012). Validation of the Spiritual Distress Assessment Tool in Older Hospitalized Patients. BMC Geriatrics, 12, 13. http://dx.doi.org/10.1186/1471-2318-12-13

Monod, S., Brennan, M., Rochat, E., Martin, E., Rochat, S., \& Bula, C. J. (2011). Instruments Measuring Spirituality in Clinical Research: A Systematic Review. Journal of General Internal Medicine, 26, 1345-1357. http://dx.doi.org/10.1007/s11606-011-1769-7

Murphy, P. E., Canada, A. L., Fitchett, G., Stein, K., Portier, K., Crammer, C., \& Peterman, A. H. (2010). An Examination 
of the 3-Factor Model and Structural Invariance across Racial/Ethnic Groups for the FACIT-Sp: A Report from the American Cancer Society’s Study of Cancer Survivors-II (SCS-II). Psycho-Oncology, 19, 264-272.

http://dx.doi.org/10.1002/pon.1559

Pargament, K. I., Koenig, H. G., \& Tarakeshwar, N. (2004). Religious Coping Methods as Predictors of Psychological, Physical and spiritual Outcomes among Medically Ill Elderly Patients: A Two-Year Longitudinal Study. Journal of Health Psychology, 9, 713-730. http://dx.doi.org/10.1177/1359105304045366

Pargament, K. I., Koenig, H. G., Tarakeshwar, N., \& Hahn, J. (2001). Religious Struggle as a Predictor of Mortality among Medically Ill Elderly Patients: A 2-Year Longitudinal Study. Archives of Internal Medicine, 161, 1881-1885. http://dx.doi.org/10.1001/archinte.161.15.1881

Peterman, A. H., Fitchett, G., Brady, M. J., Hernandez, L., \& Cella, D. (2002). Measuring Spiritual Well-Being in People with Cancer: The Functional Assessment of Chronic Illness Therapy-Spiritual Well-Being Scale (FACIT-Sp). Annals of Behavioral Medicine, 24, 49-58. http://dx.doi.org/10.1207/S15324796ABM2401_06

Puchalski, C. M. (2001). The Role of Spirituality in Health Care. Baylor University Medical Center Proceedings, 14, 352357.

Puchalski, C., Ferrell, B., Virani, R., Otis-Green, S., Baird, P., Bull, J., \& Sulmasy, D. (2009). Improving the Quality of Spiritual Care as a Dimension of Palliative Care: The Report of the Consensus Conference. Journal of Palliative Medicine, 12, 885-904. http://dx.doi.org/10.1089/jpm.2009.0142

Reker, G. T., Peacock, E. J., \& Wong, P. T. (1987). Meaning and Purpose in Life and Well-Being: A Life-Span Perspective. The Journal of Gerontology, 42, 44-49. http://dx.doi.org/10.1093/geronj/42.1.44

Rodin, G., Lo, C., Mikulincer, M., Donner, A., Gagliese, L., \& Zimmermann, C. (2009). Pathways to Distress: The Multiple Determinants of Depression, Hopelessness, and the Desire for Hastened Death in Metastatic Cancer Patients. Social Science \& Medicine, 68, 562-569. http://dx.doi.org/10.1016/j.socscimed.2008.10.037

Sessanna, L., Finnell, D. S., Underhill, M., Chang, Y. P., \& Peng, H. L. (2011). Measures Assessing Spirituality as More than Religiosity: A Methodological Review of Nursing and Health-Related Literature. Journal of Advanced Nursing, 67, 1677-1694. http://dx.doi.org/10.1111/j.1365-2648.2010.05596.x

Steinhauser, K. E., Voils, C. I., Clipp, E. C., Bosworth, H. B., Christakis, N. A., \& Tulsky, J. A. (2006). “Are You at Peace?”: One Item to Probe Spiritual Concerns at the End of Life. Archives of Internal Medicine, 166, 101-105. http://dx.doi.org/10.1001/archinte.166.1.101

Sulmasy, D. P. (2002). A Biopsychosocial-Spiritual Model for the Care of Patients at the End of Life. The Gerontologist, 42, 24-33.

Sulmasy, D. P. (2006). Spiritual Issues in the Care of Dying Patients: “...It’s Okay between Me and God”. JAMA, 296, 1385-1392. http://dx.doi.org/10.1001/jama.296.11.1385

Thune-Boyle, I. C., Stygall, J. A., Keshtgar, M. R., \& Newman, S. P. (2006). Do Religious/Spiritual Coping Strategies Affect Illness Adjustment in Patients with Cancer? A Systematic Review of the Literature. Social Science \& Medicine, 63, 151-164. http://dx.doi.org/10.1016/j.socscimed.2005.11.055

Whitford, H. S., \& Olver, I. N. (2012). The Multidimensionality of Spiritual Wellbeing: Peace, Meaning, and Faith and Their Association with Quality of Life and Coping in Oncology. Psycho-Oncology, 21, 602-610. http://dx.doi.org/10.1002/pon.1937

Yesavage, J. A., Brink, T. L., Rose, T. L., Lum, O., Huang, V., Adey, M., \& Leirer, V. O. (1982). Development and Validation of a Geriatric Depression Screening Scale: A Preliminary Report. Journal of Psychiatric Research, 17, 37-49. http://dx.doi.org/10.1016/0022-3956(82)90033-4 